\title{
Seedling Resistance to Tan Spot and Stagonospora nodorum Leaf Blotch in Wild Emmer Wheat (Triticum dicoccoides)
}

C.-G. Chu, Department of Plant Sciences, North Dakota State University, Fargo, ND 58105, USA; S. S. Xu and J. D. Faris, USDA-ARS, Northern Crop Science Laboratory, Fargo, ND 58105, USA; E. Nevo, Institute of Evolution, University of Haifa, Mt. Carmel, Haifa 31905, Israel; and T. L. Friesen, USDA-ARS, Northern Crop Science Laboratory, Fargo, ND 58105, USA

\begin{abstract}
Chu, C.-G., Xu, S. S., Faris, J. D., Nevo, E., and Friesen, T. L. 2008. Seedling resistance to tan spot and Stagonospora nodorum leaf blotch in wild emmer wheat (Triticum dicoccoides). Plant Dis. $92: 1229-1236$.

Tan spot and Stagonospora nodorum blotch (SNB), caused by Pyrenophora tritici-repentis and Stagonospora nodorum, respectively, are two destructive foliar diseases of wheat, causing significant yield reduction worldwide. The objective of this study was to evaluate 172 accessions of wild emmer wheat (Triticum dicoccoides) for seedling resistance to tan spot and SNB. All accessions were inoculated with $P$. tritici-repentis race 1 and a mixture of three diverse isolates of $S$. nodorum, respectively. The accessions were also evaluated for sensitivity to host-selective toxins (HSTs), including ToxA produced by both $S$. nodorum and P. tritici-repentis and culture filtrate produced by $S$. nodorum. A total of 34 accessions were resistant to tan spot, and 136 accessions were resistant to SNB. Among these accessions, 31 were resistant to both diseases. Significant correlations between HST insensitivity and disease resistance were observed. Our results showed that $T$. dicoccoides is a good genetic source of resistance to tan spot and SNB in wheat.
\end{abstract}

Additional keywords: Phaeosphaeria nodorum

Tan spot and Stagonospora nodorum blotch (SNB), caused by the fungi Pyrenophora tritici-repentis (Died.) Drechs. and Phaeosphaeria nodorum (E. Muller) Hedjaroude (anamorph: Stagonospora nodorum (Berk.) Castellani \& E.G. Germano), respectively, are two destructive foliar diseases of common wheat (Triticum aestivum L.) and durum wheat (T. turgidum L. subsp. durum). Both diseases can cause yield losses as high as $50 \%(13,40)$. Due to the application of reduced tillage practices in cereal growing regions such as the United States, tan spot and SNB have become very common in recent years. Tan spot was identified as the most prevalent disease of wheat in Canada in 2003 (46),

Corresponding author: Timothy L. Friesen

E-mail: timothy.friesen@ars.usda.gov

Mention of trade names or commercial products in this article is solely for the purpose of providing specific information and does not imply recommendation or endorsement by the U.S. Department of Agriculture.

* The $\boldsymbol{e}$-Xtra logo stands for "electronic extra" and indicates that Figure 1 appears in color in the online edition.

Accepted for publication 18 December 2007.

doi:10.1094/PDIS-92-8-1229

This article is in the public domain and not copyrightable. It may be freely reprinted with customary crediting of the source. The American Phytopathological Society, 2008. and Perello et al. (38) indicated that tan spot had become more destructive in the southern Cone region of South America including Argentina, Brazil, Chile, Paraguay, and Uruguay.

Compared to the use of fungicides, breeding for disease resistance is more cost effective, socially feasible, and environmentally safe for growers. Unfortunately, due to the narrow genetic base, the majority of current bread and durum wheat cultivars are susceptible to both diseases $(24,42,43,45)$. Rees and Platz (39) evaluated 1,400 bread wheat lines for resistance to $P$. tritici-repentis and found no complete resistance. Alam and Gustafson (1) screened 212 accessions of eight diploid and 10 polyploid species of Aegilops and found almost no resistance to tan spot. Some partial resistance to SNB had been detected in wild relatives of wheat, such as T. timopheevii (29), T. monococcum (28), A. tauschii (28), A. speltoides (8), and A. longissima (9). Until recently, few germplasms or cultivars with good resistance were reported. Xu et al. (51) evaluated 120 elite synthetic hexaploid wheat (SHW) lines and 35 durum lines for seedling resistance to both tan spot and SNB and found that about 47 and $30 \%$ of synthetic lines showed good resistance to tan spot and SNB, respectively. Mergoum et al. (33) identified three cultivars and 12 advanced breeding lines resistant to SNB. Other germplasm resistant to tan spot and/or SNB have also been identified in other reports $(42,43,45)$. However, to control both diseases more effectively in the long term, the identification and utilization of novel resistance genes from wheat relatives would increase the genetic diversity and broaden the genetic base of resistance.

During the development of disease, $P$. tritici-repentis can produce several hostselective toxins (HST) that induce necrosis or chlorosis in sensitive wheat genotypes. To date, five toxins of $P$. tritici-repentis, designated Ptr ToxA (47), Ptr ToxB $(31,37)$, Ptr ToxC $(10)$, and two different toxins simultaneously named Ptr ToxD $(30,32)$, have been reported. Ptr ToxA $(5,47,48,49,52)$ and Ptr ToxB (31) have been well characterized. The dominant gene, Tsnl, which is located on wheat chromosome arm 5BL, controls sensitivity to Ptr ToxA (11), and genotypes without Tsnl are insensitive to the toxin (3). Host insensitivity to Ptr ToxA has been found to be associated with resistance to $P$. triticirepentis races 1 and $2(14,23)$.

S. nodorum also produces several HSTs such as SnToxA (18), SnTox1 (26,27), SnTox2 (16), and SnTox3 (19). Correlations between toxin insensitivity and resistance to SNB have been reported $(16,18,26,27)$. Liu et al. $(26,27)$ partially purified a toxin designated SnTox1 and identified the recessive host gene, snnl, which conferred insensitivity to the toxin. The snnl locus mapped to chromosome arm 1BS in the International Triticeae Mapping Initiative (ITMI) population, and explained as much as $58 \%$ of the phenotypic variation in SNB. Friesen et al. (18) reported that the gene encoding Ptr ToxA in $P$. tritici-repentis was transferred from $S$. nodorum just before 1941, and the sequence similarity between the SnToxA and PtrToxA genes was as high as $99.7 \%$. A strong correlation between SnToxA insensitivity and SNB resistance was found, and the $t s n 1$ locus explained as much as $68 \%$ of the variation, indicating that a compatible $T s n 1-S n T o x A$ interaction plays a major role in disease development (18).

Wild emmer wheat, $T$. dicoccoides (AABB, $2 n=4 x=28$ ), distributed over the Near East Fertile Crescent, is a wild progenitor of cultivated durum and bread wheat (53). The A and B genomes of durum and bread wheat were derived from $T$. dicoccoides, and crosses between them are fully fertile, making genes from $T$. dicoc- 
coides readily transferable to cultivated wheat through homologous chromosome recombination $(7,35,50)$. T. dicoccoides has been shown to be a good genetic source for resistance to powdery mildew, leaf rust, stem rust, and Fusarium head blight, as well as increased seed storage protein content $(4,20,36,44)$. In this research, we evaluated potential sources of resistance to tan spot and SNB from $T$. dicoccoides at the seedling stage under controlled conditions.

\section{MATERIALS AND METHODS}

Plant materials. A total of 172 accessions of $T$. dicoccoides were evaluated. Among them, 166 were collected from different locations in Israel and Turkey (34) and introduced to the United States by Leonard Joppa (USDA-ARS, Fargo, ND) (21). These accessions are currently maintained at the Institute of Evolution, University of Haifa, Israel and at the USDA-ARS, Northern Crop Science Laboratory, Fargo, ND. The remaining six accessions (PI272582, PI343446, PI352328, PI355459, PI428109, and PI466995) were obtained from the USDA-ARS, National Small Grains Research Facility, National Small Grains Collection, Aberdeen, ID. In addition, the International Maize and Wheat Improvement Center (CIMMYT) SHW line W-7976 and the North Dakota hard red spring wheat cultivar Grandin were used as resistant and susceptible checks, respectively.

Evaluation of reaction to $P$. triticirepentis and Ptr ToxA. Evaluation of reaction to $P$. tritici-repentis was conducted under controlled greenhouse and growth chamber conditions using experimental procedures described by Friesen et al. (14). Seeds of all accessions were planted in super-cell Cone-tainers (Stuewe and Sons, Inc., Corvallis, OR) with sunshine SB100 (Sun Gro Horticulture, Bellevue, WA) and fertilized with Osmocote Plus 15-19-12 (Scotts Sierra Horticultural Product Company, Marysville, OH). Three seeds were planted in each cone, and each accession was planted in three cones in each of three experiments. Therefore, a total of 27 plants from each accession were tested. Cones were placed in RL98 trays (Stuewe and Sons). To eliminate any edge effect, the susceptible cultivar Grandin was planted in all the cones around the borders on each RL98 tray except for three cones for planting the resistant check W-7976.

At the two- to three-leaf stage, the secondary leaves from three plants of each accession were infiltrated with purified Ptr ToxA (provided by S. W. Meinhardt, Department of Plant Pathology, North Dakota State University, Fargo). Ptr ToxA was originally purified from $P$. tritici-repentis race 2 (isolate 86-124) as described by Zhang et al. (52). Toxin infiltration was done according to $\mathrm{Xu}$ et al. (51). Approximately $20 \mu \mathrm{l}$ of toxin $\left(10 \mu \mathrm{g} \mathrm{ml}^{-1}\right)$ was infiltrated into the secondary leaf using a 1 -ml syringe with the needle removed. The boundaries of the infiltration sites were marked with a nontoxic felt pen. Leaves were evaluated 4 days after infiltration and scored as insensitive (-) or sensitive (+) based on the absence or presence of necrosis, respectively.

After sensitivity to Ptr ToxA was tested, all plants, including those that had been infiltrated, were inoculated with conidia of the $P$. tritici-repentis isolate Pti2, a race 1 isolate obtained from a wheat field in South Dakota (17). A race 1 isolate was chosen due to its prevalence in North America (2), and because it contains the known virulence factors found in race 2 (25), the second most prevalent race found in the field (2). Preparation of inoculum and inoculations were done as described in $\mathrm{Xu}$ et al. (51). Briefly, the fungus was grown on V8-potato dextrose agar (PDA) plates $(150 \mathrm{ml} \mathrm{V8}$ juice, $10 \mathrm{~g}$ PDA, $3 \mathrm{~g}$ $\mathrm{CaCO}_{3}, 10 \mathrm{~g}$ agar, and $850 \mathrm{ml}$ distilled water) in the dark for 4 to 5 days at $20^{\circ} \mathrm{C}$. After flooding the plates with sterile distilled water, the plates were incubated under fluorescent light for $24 \mathrm{~h}$ at 20 to $22^{\circ} \mathrm{C}$ followed by 18 to $24 \mathrm{~h}$ in the dark at $16^{\circ} \mathrm{C}$. The conidial inoculum suspension was obtained by washing the plates with distilled water and scraping the spores from the plates with a sterile inoculating loop. The final inoculum concentration was adjusted to 3,000 spores $\mathrm{ml}^{-1}$. Plants were inoculated until runoff with a handheld sprayer. Disease reaction types were rated 7 days postinoculation using the 1 to 5 lesion-type rating scale developed by Lamari and Bernier (22), with 1 being resistant, 2 moderately resistant, 3 moderately resistant/moderately susceptible, 4 susceptible, and 5 highly susceptible. Lines showing equal numbers of two lesion types were given an intermediate reaction type (e.g., reaction types 1 and 2 equal 1.5).

Evaluation of reactions to $S$. nodorum and $S$. nodorum HSTs. The experimental design used for evaluating reaction to $S$. nodorum inoculations was the same as that described for $P$. tritici-repentis. Inoculum preparation was done according to $\mathrm{Xu}$ et al. (51) except that three $S$. nodorum isolates, LDNSn4, BBCSn5, and Sn2000, were used to produce pycnidiospores. The fungus was grown on V8-PDA medium for 7 days, and inoculum suspension was obtained by adding sterile distilled water and scraping the spores off the plate surface with an inoculating loop and adjusting the inoculum concentration to $1 \times 10^{6}$ spores $\mathrm{ml}^{-1}$. The inoculum suspensions of the three isolates were then mixed equally before inoculation. Isolate Sn2000, collected from a North Dakota wheat field in 1980, was chosen because it has been used to screen North Dakota germplasm and breeding lines and has been shown to be an aggressive toxin-producing isolate
(18,26,27). Isolates LDNSn4 and BBCSn5 were collected in North Dakota and Minnesota, respectively, and were used because they produce other toxins in addition to those produced by $\mathrm{Sn} 2000$ (T. L. Friesen, unpublished data). Therefore, these mixtures provide a diversity of virulence factors present in $S$. nodorum. The rating scale used for $S$. nodorum is a 0 to 5 numerical scale based on lesion type as described in Liu et al. (27), where $0=$ highly resistant (absence of visible lesions); $1=$ resistant (few penetration points, with lesions consisting of flecking or small dark spots); $2=$ moderately resistant (lesions consisting of dark spots with little surrounding necrosis or chlorosis); 3 $=$ moderately susceptible (dark lesions completely surrounded by necrosis or chlorosis, lesions 2 to $3 \mathrm{~mm}$ ); 4 = susceptible (larger necrotic or chlorotic lesions, 4 $\mathrm{mm}$ or greater, with little coalescence); and $5=$ highly susceptible (large coalescent lesions with very little green tissue remaining). Plants having equal numbers of two different lesion types were given an intermediate lesion type (e.g., lesion types 1 and 2 equal 1.5).

Because SnToxA is functionally identical to Ptr ToxA (18), the results from Ptr ToxA infiltration were used to infer reactions to SnToxA. Isolate Sn2000 has been shown to produce SnToxA (18), SnTox1 $(26,27)$, and several additional toxins in culture (T. L. Friesen, unpublished data); however, only SnToxA has been purified. Therefore, culture filtrate of Sn2000KO61 , a genetically modified strain of the isolate Sn2000 with a disrupted ToxA gene (18), was used for investigation of the reaction to $S$. nodorum toxins in the absence of SnToxA. Culture filtrates were produced as described by Liu et al. (26). Briefly, $200 \mu \mathrm{l}$ of Sn2000KO6-1 spore suspension was added to $60 \mathrm{ml}$ of liquid Fries medium ( $5 \mathrm{~g}$ of ammonium tartrate, $1.0 \mathrm{~g}$ of ammonium nitrate, $0.5 \mathrm{~g}$ of magnesium sulfate, $1.3 \mathrm{~g}$ of potassium phosphate [dibasic], $2.6 \mathrm{~g}$ of potassium phosphate [monobasic], $30.0 \mathrm{~g}$ of sucrose, $1.0 \mathrm{~g}$ of yeast extract, dissolved in $1,000 \mathrm{ml}$ of water) and placed on an orbital shaker at $80 \mathrm{rpm}$ for $48 \mathrm{~h}$ followed by 3 weeks of stationary growth. Both growth steps took place in the dark at room temperature. Culture filtrate was filtered through two layers of cheesecloth followed by vacuum filtration through a Whatman No. 1 filter and a $0.45-\mu \mathrm{m}$ Whatman filter.

Statistical analysis. Statistical analysis was done using the Statistical Analysis System version 9.1 (41). Bartlett's $\chi^{2}$ was calculated to test the homogeneity of variance among experiments. A two-sample $t$ test was used to test the difference of average reactions to $P$. tritici-repentis and $S$. nodorum according to the reactions to HSTs. The least significant difference (LSD) was used to test for significant differences among the accessions. Regression 
analysis was performed to evaluate the association of sensitivity to HSTs with average reaction to $P$. tritici-repentis and $S$. nodorum. For regression analysis, a value of 1 was given to accessions that were sensitive to HSTs, and a value of 0 for accessions that were insensitive.

\section{RESULTS}

Reaction to $P$. tritici-repentis and Ptr ToxA. Average tan spot reaction types in all $T$. dicoccoides accessions ranged from 1.2 to 4.7 with susceptible (Grandin) and resistant (W-7976) controls having average disease reaction types of 4.5 and 1.3 , respectively (Fig. 1). Bartlett's $\chi^{2}$ test showed homogeneity among three experiments $\left(\chi_{\mathrm{df}=2}^{2}=0.26, P=0.88\right)$; therefore, results from the three experiments were combined (Tables 1 and 2). Almost half of the $T$. dicoccoides accessions were susceptible, with average disease reactions ranging from 3.0 to 4.0. Among the susceptible lines, 12 were highly susceptible with average disease reactions greater than 4.0. Therefore, the majority of the accessions of $T$. dicoccoides tested were susceptible to $\tan$ spot. However, 34 accessions had an average disease reaction of less than 2 , and of these, 21 accessions had an average disease reaction lower than 1.5 , demonstrating that $T$. dicoccoides is a potential source of tan spot resistance.

Of the 172 accessions tested, 149 were insensitive to Ptr ToxA and 23 were sensitive (Tables 1 and 2, Figs. 1 and 2), indicating that only 23 of the lines carried the dominant $T s n 1$ allele, which confers sensitivity to Ptr ToxA (11). All 34 resistant accessions were insensitive to Ptr ToxA (Tables 1 and 2, Figs. 1 and 2). Ptr ToxA insensitive accessions showed an average tan spot reaction type of 2.89 , whereas accessions sensitive to Ptr ToxA had an average reaction of 3.41. A two-sample $t$ test indicated that the difference between these two average disease reactions $(0.52)$ was highly significant $(P<0.0001)$ (Table 3), demonstrating that the absence of $T s n 1$ can significantly increase resistance to tan spot. Simple linear regression analysis between insensitivity to Ptr ToxA and resistance to tan spot showed a $3 \%$ association $\left(R^{2}=0.03, P<0.0001\right)$, indicating a weak but significant association between Ptr ToxA insensitivity and tan spot resistance. Therefore, genes other than Tsn1/tsn1 are most likely also involved in governing susceptibility/resistance to tan spot in T. dicoccoides.

Reaction to $S$. nodorum, SnToxA, and S. nodorum culture filtrates. Bartlett's $\chi^{2}$ test for homogeneity among experiments of the $S$. nodorum inoculations showed that three experiments were homogeneous $\left(\chi_{\mathrm{df}=2}^{2}=0.98, P=0.61\right)$. Therefore, the disease reaction types from the three experiments were combined. Reactions to $S$. nodorum among the $T$. dicoccoides accessions were quite different from those of $P$. tritici-repentis (Tables 1 and 2). Of the 172 accessions, 136 had average disease reaction types less than 2.0, and 80 of these were less than 0.5 , indicating that most of the $T$. dicoccoides accessions were resistant to SNB. In addition, 31 of the 136 SNB-resistant accessions had tan spot reaction types less than 2.0 (Table 2), indicating that these accessions are promising sources for resistance to both tan spot and SNB.

Reactions to toxins produced by $S$. nodorum were strongly associated with SNB disease reactions. The average SNB reaction types ( 0 to 5 scale), separated based on reaction to SnToxA, were 0.84 for insensitive $\left(\mathrm{SnToxA}^{-}\right)$accessions and
3.17 for sensitive $\left(\mathrm{SnToxA}^{+}\right)$accessions, and the difference (2.33) between these two classes is highly significant $(P<$ 0.0001 , Table 3 ). Only two accessions with disease reaction types less than 2 were SnToxA sensitive (Tables 1 and 2, Fig. 3).

For Sn2000KO6-1 culture filtrate infiltrations, 64 of the 172 accessions were insensitive (Tables 1 and 2). The difference of the average SNB reaction types between accessions that were culture filtrate sensitive $\left(\mathrm{CF}^{+}\right)$versus insensitive $\left(\mathrm{CF}^{-}\right)$was $0.71(P<0.0001)$ (Table 3$)$. Sixty of the 64 insensitive accessions had average SNB reaction types less than 2 , and all 24 accessions with average SNB reaction types greater than 2.5 were sensitive (Tables 1

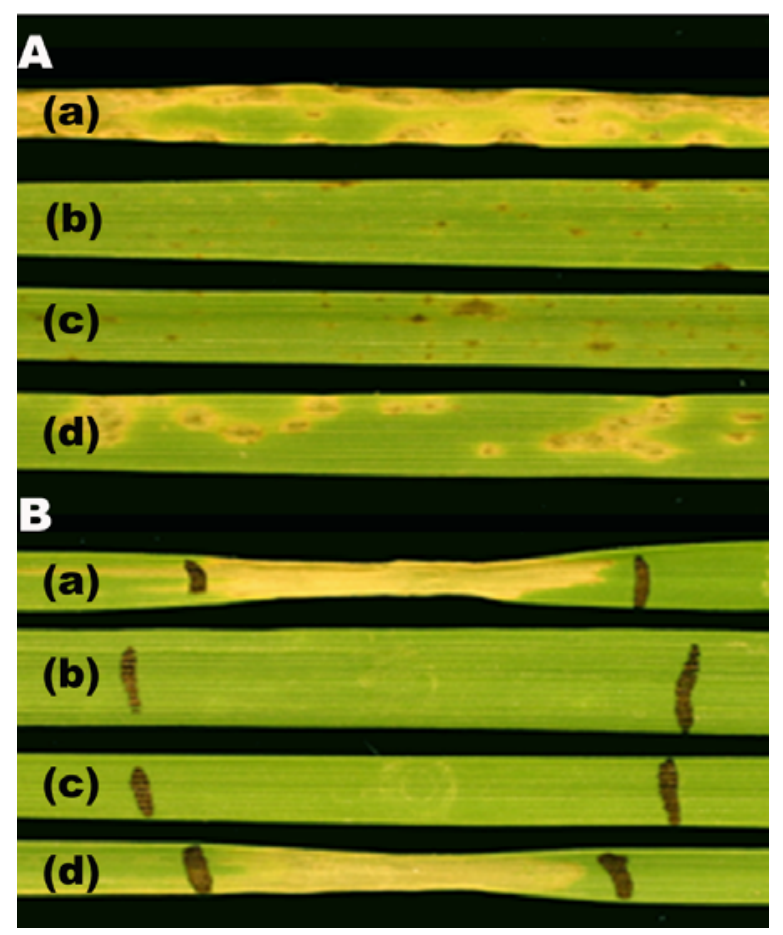

Fig. 1. Reaction of Pyrenophora tritici-repentis inoculation (A) and Ptr ToxA infiltration (B). Resistant and susceptible checks: (a) Grandin (susceptible and Ptr ToxA sensitive) and (b) W7976 (resistant and Ptr ToxA insensitive); Triticum dicoccoides accessions: (c) B-35 (resistant and Ptr ToxA insensitive) and (d) 18-1 (susceptible and Ptr ToxA sensitive).

Table 1. Reaction to inoculation of conidia and infiltration of host selective toxins produced by Pyrenophora tritici-repentis (Ptr) and Stagonospora nodorum (Sn) in 172 Triticum dicoccoides accessions

\begin{tabular}{|c|c|c|c|c|c|}
\hline \multirow[b]{3}{*}{ Disease rating } & \multicolumn{5}{|c|}{ Number of accessions } \\
\hline & \multicolumn{2}{|c|}{ Reaction to Ptra } & \multicolumn{3}{|c|}{ Reaction to $\mathbf{S n}^{b}$} \\
\hline & Inoculation & $\operatorname{Ptr} \operatorname{Tox} A^{-}$ & Inoculation & SnToxA $^{-}$ & $\mathrm{CF}^{-}$ \\
\hline $0-0.5$ & & & 80 & 79 & 35 \\
\hline $0.5-1$ & & & 28 & 28 & 14 \\
\hline $1-1.5$ & 21 & 21 & 17 & 17 & 9 \\
\hline $1.5-2$ & 13 & 13 & 11 & 10 & 2 \\
\hline $2-2.5$ & 10 & 10 & 12 & 9 & 4 \\
\hline $2.5-3$ & 33 & 32 & 6 & 1 & 0 \\
\hline $3-3.5$ & 54 & 38 & 8 & 1 & 0 \\
\hline $3.5-4$ & 29 & 24 & 5 & 4 & 0 \\
\hline $4-4.5$ & 11 & 10 & 3 & 0 & 0 \\
\hline $4.5-5$ & 1 & 1 & 2 & 0 & 0 \\
\hline
\end{tabular}

a Ptr ToxA- means Ptr ToxA insensitive.

b SnToxA $\mathrm{A}^{-}$and $\mathrm{CF}^{-}$means SnToxA and $\mathrm{CF}$ insensitive, respectively; $\mathrm{CF}=$ culture filtrate produced by Sn2000KO6-1. 
and 2, Fig. 3), indicating that toxins produced in the Sn2000KO6-1 culture filtrate were important for disease development. To compare the association between SnToxA- and culture filtrate-insensitivity to that of $S$. nodorum resistance separately, the average SNB scores among the four classes involving reaction to culture filtrate $(\mathrm{CF})$ and SnToxA (SnToxA ${ }^{-} \mathrm{CF}^{-}$ versus $\mathrm{SnToxA}^{-} \mathrm{CF}^{+}$, $\mathrm{SnToxA}^{+} \mathrm{CF}^{-}$versus SnToxA $\mathrm{A}^{+} \mathrm{CF}^{+}, \quad \mathrm{SnToxA}^{-} \mathrm{CF}^{-}$versus SnToxA ${ }^{+} \mathrm{CF}^{-}$, and $\mathrm{SnToxA}^{-} \mathrm{CF}^{+}$versus SnTox $\mathrm{A}^{+} \mathrm{CF}^{+}$) were analyzed using a twosample $t$ test. All comparisons were significantly different at the $P<0.0001$ level of probability (Table 3 ). Therefore, both SnToxA and other toxins present in the Sn2000KO6-1 culture filtrate play a significant role in the development of SNB among the $T$. dicoccoides accessions.

Results from regression analysis confirmed the association between reactions to HSTs and $S$. nodorum. Associations between SnToxA and SNB $\left(R^{2}=0.40, P<\right.$ $0.0001)$ and between SNB and culture filtrate $\left(R^{2}=0.07, P<0.0001\right)$ were 40 and $7 \%$, respectively, suggesting that resistance to $\mathrm{SNB}$ in $T$. dicoccoides is largely governed by $t s n 1$ on chromosome $5 \mathrm{~B}$, as well as additional loci at other genomic regions that govern insensitivity to toxins present in the Sn2000KO6-1 culture filtrate. Multiple regression analysis of SNB severity and reaction to SnToxA and culture filtrate showed the association was increased to $43 \%\left(R^{2}=0.43, P<0.0001\right)$. The average disease reactions of accessions insensitive to both SnToxA and culture filtrate is 0.63 , which is significantly different from that of accessions sensitive to at least one toxin $(P<0.0001$, Table 3$)$. Therefore, the resistance conferred by toxin insensitivity loci such as tsnl on chromosome $5 \mathrm{~B}$ and that of others appears to be additive.

\section{DISCUSSION}

Here, we identified a number of $T$. dicoccoides accessions with good levels of resistance to tan spot and SNB. These accessions can be used for the development of disease-resistant germplasm. The 31 accessions that showed good resistance to both diseases will be especially useful.

Correlation between insensitivity to $\mathrm{Ptr}$ ToxA and resistance to tan spot in hexaploid wheat has been identified. Friesen et al. (14) found that the Ptr ToxA reaction accounted for $24.4 \%$ of the variation in $\tan$ spot using a Ptr ToxA producing race 2 isolate. $\mathrm{Xu}$ et al. (51) found a $10 \%$ association between insensitivity to Ptr ToxA and resistance to tan spot among 120 SHW lines. Our research indicated a weak but significant association between Ptr ToxA insensitivity and disease resistance $\left(R^{2}=\right.$ $0.03, P<0.0001)$, but all accessions with high levels of resistance were Ptr ToxA insensitive (Table 2). This demonstrates that insensitivity to Ptr ToxA can increase
Table 2. Seedling reactions to Pyrenophora tritici-repentis (Ptr) and Stagonospora nodorum ( $\mathrm{Sn}$ ) in 172 Triticum dicoccoides accessions

\begin{tabular}{|c|c|c|c|c|}
\hline Accession $^{a}$ & Tan spot mean & Ptr/Sn ToxA ${ }^{b}$ & SNB $^{c}$ mean & Culture filtrate $e^{b, d}$ \\
\hline \multicolumn{5}{|l|}{ Checks } \\
\hline W7976 & $1.30 \pm 0.29$ & - & $1.00 \pm 0.00$ & + \\
\hline Grandin & $4.50 \pm 0.00$ & + & $4.30 \pm 0.29$ & + \\
\hline \multicolumn{5}{|c|}{ Resistant to both tan spot and SNB } \\
\hline $20-35$ & $1.20 \pm 0.29$ & - & $0.30 \pm 0.58$ & + \\
\hline $16-1$ & $1.20 \pm 0.29$ & - & $0.70 \pm 0.29$ & - \\
\hline I-15 & $1.20 \pm 0.29$ & - & $0.80 \pm 0.29$ & - \\
\hline I- 29 & $1.20 \pm 0.29$ & - & $1.20 \pm 0.29$ & - \\
\hline B-35 & $1.20 \pm 0.29$ & - & $1.30 \pm 0.76$ & - \\
\hline A-82 & $1.30 \pm 0.29$ & - & $0.20 \pm 0.29$ & - \\
\hline $\mathrm{I}-20$ & $1.30 \pm 0.29$ & - & $1.20 \pm 0.58$ & + \\
\hline $\mathrm{I}-18$ & $1.30 \pm 0.29$ & - & $1.30 \pm 0.29$ & - \\
\hline $\mathrm{I}-50$ & $1.30 \pm 0.29$ & - & $1.30 \pm 0.29$ & + \\
\hline $32-45$ & $1.30 \pm 0.58$ & - & $1.20 \pm 2.02$ & - \\
\hline B-34 & $1.30 \pm 0.58$ & - & $1.30 \pm 0.76$ & _- \\
\hline B-6 & $1.30 \pm 0.58$ & - & $1.70 \pm 1.04$ & - \\
\hline $16-29$ & $1.50 \pm 0.00$ & - & $0.80 \pm 0.29$ & + \\
\hline L-1 & $1.50 \pm 0.00$ & - & $1.50 \pm 0.87$ & - \\
\hline A-33 & $1.50 \pm 0.50$ & - & $0.20 \pm 0.29$ & + \\
\hline B-8 & $1.50 \pm 0.50$ & - & $0.20 \pm 0.29$ & - \\
\hline A-61 & $1.50 \pm 0.50$ & - & $0.70 \pm 0.29$ & - \\
\hline $\mathrm{I}-17$ & $1.50 \pm 0.50$ & - & $0.70 \pm 0.29$ & - \\
\hline $\mathrm{I}-45$ & $1.50 \pm 0.50$ & - & $1.80 \pm 0.29$ & + \\
\hline K-50 & $1.70 \pm 0.29$ & - & $0.20 \pm 0.29$ & + \\
\hline A-52 & $1.70 \pm 0.29$ & - & $0.30 \pm 0.29$ & - \\
\hline B-31 & $1.70 \pm 0.29$ & - & $0.50 \pm 0.50$ & - \\
\hline L-29 & $1.70 \pm 0.29$ & - & $0.80 \pm 0.29$ & + \\
\hline L-33 & $1.70 \pm 0.29$ & - & $1.00 \pm 0.00$ & + \\
\hline $18-48$ & $1.80 \pm 0.29$ & _- & $0.30 \pm 0.29$ & + \\
\hline L-43 & $1.80 \pm 0.29$ & - & $1.20 \pm 0.58$ & + \\
\hline A-56 & $2.00 \pm 0.00$ & - & $0.80 \pm 0.29$ & - \\
\hline F-25 & $2.00 \pm 0.50$ & - & $0.20 \pm 0.29$ & + \\
\hline $18-24$ & $2.00 \pm 0.50$ & - & $0.70 \pm 0.29$ & - \\
\hline L-34 & $2.00 \pm 0.50$ & _- & $1.00 \pm 0.00$ & + \\
\hline $\mathrm{L}-40$ & $2.00 \pm 0.50$ & - & $1.00 \pm 0.50$ & + \\
\hline \multicolumn{5}{|c|}{ Resistant to tan spot only } \\
\hline B-32 & $1.30 \pm 0.29$ & - & $2.30 \pm 0.29$ & - \\
\hline I-4 & $1.50 \pm 0.50$ & - & $2.30 \pm 0.29$ & + \\
\hline $32-29$ & $1.70 \pm 0.29$ & - & $2.20 \pm 0.29$ & - \\
\hline \multicolumn{5}{|c|}{ Resistant to SNB only } \\
\hline $\mathrm{C}-27$ & $2.30 \pm 0.29$ & - & $0.00 \pm 0.00$ & - \\
\hline $17-22$ & $2.70 \pm 0.29$ & - & $0.00 \pm 0.00$ & + \\
\hline $15-17$ & $2.80 \pm 0.29$ & - & $0.00 \pm 0.00$ & - \\
\hline $18-49$ & $2.80 \pm 0.29$ & - & $0.00 \pm 0.00$ & + \\
\hline $15-32$ & $3.30 \pm 0.29$ & - & $0.00 \pm 0.00$ & + \\
\hline F-28 & $3.80 \pm 0.29$ & - & $0.00 \pm 0.00$ & + \\
\hline F-18 & $4.20 \pm 0.29$ & - & $0.00 \pm 0.00$ & + \\
\hline $15-19$ & $2.50 \pm 0.00$ & - & $0.20 \pm 0.29$ & - \\
\hline $15-2$ & $2.50 \pm 0.00$ & - & $0.20 \pm 0.29$ & + \\
\hline $15-37$ & $2.50 \pm 0.00$ & - & $0.20 \pm 0.29$ & + \\
\hline $19-25$ & $2.50 \pm 0.00$ & - & $0.20 \pm 0.29$ & + \\
\hline $19-29$ & $2.70 \pm 0.29$ & - & $0.20 \pm 0.29$ & - \\
\hline $14-2$ & $2.80 \pm 0.29$ & - & $0.20 \pm 0.29$ & + \\
\hline $15-43$ & $2.80 \pm 0.29$ & - & $0.20 \pm 0.29$ & - \\
\hline $19-45$ & $2.80 \pm 0.29$ & - & $0.20 \pm 0.29$ & - \\
\hline $19-50$ & $2.80 \pm 0.29$ & - & $0.20 \pm 0.29$ & - \\
\hline $14-45$ & $3.00 \pm 0.00$ & - & $0.20 \pm 0.29$ & + \\
\hline $36-33$ & $3.00 \pm 0.00$ & - & $0.20 \pm 0.29$ & - \\
\hline $14-13$ & $3.00 \pm 0.50$ & - & $0.20 \pm 0.29$ & + \\
\hline $15-1$ & $3.00 \pm 0.50$ & - & $0.20 \pm 0.29$ & - \\
\hline $19-20$ & $3.00 \pm 0.50$ & - & $0.20 \pm 0.29$ & - \\
\hline $19-36$ & $3.00 \pm 0.50$ & - & $0.20 \pm 0.29$ & - \\
\hline $19-51$ & $3.00 \pm 0.50$ & - & $0.20 \pm 0.29$ & _- \\
\hline $19-7$ & $3.00 \pm 0.50$ & - & $0.20 \pm 0.29$ & + \\
\hline
\end{tabular}

a Accessions: W-7976 and Grandin are the resistant and susceptible checks, respectively; PI stands for plant identification, and the PI accessions were from the USDA National Small Grains Collection in Aberdeen, ID, USA; all others are accession numbers of the Institute of Evolution, University of Haifa, Israel, and were introduced to the United States by Leonard Joppa (USDA-ARS, Fargo, ND).

${ }^{\mathrm{b}}$ Reaction to Ptr/Sn ToxA and culture filtrate: insensitive (-), sensitive (+).

${ }^{\mathrm{c}}$ Stagonospora nodorum blotch.

${ }^{\mathrm{d}}$ Culture filtrate was produced by Sn2000KO6-1, a strain derived from Sn2000 by mutating the ToxA gene. 
Table 2. (continued from previous page)

\begin{tabular}{|c|c|c|c|c|}
\hline Accession $^{a}$ & Tan spot mean & Ptr/Sn ToxA ${ }^{b}$ & $\mathrm{SNB}^{\mathrm{c}}$ mean & Culture filtrate $^{b, d}$ \\
\hline $14-47$ & $3.20 \pm 0.29$ & - & $0.20 \pm 0.29$ & + \\
\hline $15-18$ & $3.20 \pm 0.29$ & - & $0.20 \pm 0.29$ & - \\
\hline $32-46$ & $3.20 \pm 0.29$ & - & $0.20 \pm 0.29$ & + \\
\hline F-3 & $3.20 \pm 0.29$ & - & $0.20 \pm 0.29$ & + \\
\hline K-45 & $3.20 \pm 0.29$ & - & $0.20 \pm 0.29$ & + \\
\hline $\mathrm{T}-7-40$ & $3.20 \pm 0.29$ & - & $0.20 \pm 0.29$ & - \\
\hline $17-2$ & $3.20 \pm 0.76$ & - & $0.20 \pm 0.29$ & + \\
\hline $19-23$ & $3.20 \pm 0.76$ & - & $0.20 \pm 0.29$ & + \\
\hline $15-52$ & $3.30 \pm 0.29$ & - & $0.20 \pm 0.29$ & - \\
\hline $18-15$ & $3.30 \pm 0.29$ & - & $0.20 \pm 0.29$ & - \\
\hline $15-26$ & $3.30 \pm 0.58$ & - & $0.20 \pm 0.29$ & + \\
\hline $19-6$ & $3.30 \pm 0.58$ & - & $0.20 \pm 0.29$ & + \\
\hline C-55 & $3.50 \pm 0.00$ & - & $0.20 \pm 0.29$ & - \\
\hline $18-20$ & $3.50 \pm 0.50$ & + & $0.20 \pm 0.29$ & - \\
\hline $14-36$ & $3.70 \pm 0.29$ & - & $0.20 \pm 0.29$ & + \\
\hline F-38 & $3.70 \pm 0.58$ & - & $0.20 \pm 0.29$ & + \\
\hline F-65 & $3.80 \pm 0.29$ & - & $0.20 \pm 0.29$ & + \\
\hline C-21 & $4.20 \pm 0.58$ & - & $0.20 \pm 0.29$ & + \\
\hline F-43 & $4.30 \pm 0.29$ & - & $0.20 \pm 0.29$ & + \\
\hline C-30 & $2.80 \pm 0.29$ & - & $0.30 \pm 0.29$ & - \\
\hline PI272582 & $2.80 \pm 0.29$ & - & $0.30 \pm 0.29$ & - \\
\hline $19-24$ & $2.80 \pm 0.58$ & - & $0.30 \pm 0.29$ & + \\
\hline PI343446 & $3.00 \pm 0.50$ & - & $0.30 \pm 0.29$ & - \\
\hline B-13 & $3.20 \pm 0.58$ & - & $0.30 \pm 0.29$ & - \\
\hline F-7 & $3.30 \pm 0.29$ & - & $0.30 \pm 0.29$ & + \\
\hline $14-34$ & $3.50 \pm 0.50$ & - & $0.30 \pm 0.29$ & + \\
\hline $14-35$ & $3.70 \pm 1.04$ & - & $0.30 \pm 0.29$ & - \\
\hline F-37 & $3.80 \pm 0.29$ & - & $0.30 \pm 0.29$ & + \\
\hline F-81 & $3.80 \pm 0.29$ & - & $0.30 \pm 0.29$ & + \\
\hline $14-25$ & $4.00 \pm 0.50$ & - & $0.30 \pm 0.29$ & - \\
\hline $14-40$ & $4.00 \pm 0.50$ & - & $0.30 \pm 0.29$ & - \\
\hline K-36 & $4.20 \pm 0.29$ & - & $0.30 \pm 0.29$ & - \\
\hline C-19 & $4.50 \pm 0.50$ & - & $0.30 \pm 0.29$ & + \\
\hline $32-44$ & $2.30 \pm 0.29$ & - & $0.30 \pm 0.58$ & + \\
\hline $17-1$ & $2.50 \pm 0.00$ & - & $0.30 \pm 0.58$ & + \\
\hline A-35 & $2.50 \pm 0.00$ & - & $0.30 \pm 0.58$ & + \\
\hline $18-37$ & $2.70 \pm 0.29$ & - & $0.50 \pm 0.00$ & + \\
\hline L-10 & $3.00 \pm 0.50$ & - & $0.50 \pm 0.00$ & + \\
\hline $15-55$ & $3.20 \pm 0.29$ & - & $0.50 \pm 0.00$ & - \\
\hline A-57 & $3.20 \pm 0.29$ & - & $0.50 \pm 0.00$ & + \\
\hline K-32 & $3.20 \pm 0.29$ & - & $0.50 \pm 0.00$ & - \\
\hline PI352328 & $3.20 \pm 0.58$ & - & $0.50 \pm 0.00$ & - \\
\hline I-39 & $3.50 \pm 0.50$ & - & $0.50 \pm 0.00$ & - \\
\hline $14-49$ & $3.70 \pm 0.29$ & - & $0.50 \pm 0.00$ & + \\
\hline B-16 & $3.70 \pm 1.04$ & - & $0.50 \pm 0.00$ & - \\
\hline PI466995 & $4.00 \pm 0.50$ & - & $0.50 \pm 0.00$ & + \\
\hline $\mathrm{C}-7$ & $3.80 \pm 1.04$ & - & $0.50 \pm 0.50$ & + \\
\hline B-40 & $2.50 \pm 0.50$ & - & $0.70 \pm 0.29$ & + \\
\hline PI355459 & $2.80 \pm 0.29$ & - & $0.70 \pm 0.29$ & + \\
\hline L-25 & $3.50 \pm 0.00$ & - & $0.70 \pm 0.29$ & - \\
\hline G-47 & $3.80 \pm 1.04$ & - & $0.70 \pm 0.29$ & - \\
\hline C-36 & $4.20 \pm 1.04$ & - & $0.70 \pm 0.29$ & + \\
\hline B-19 & $2.70 \pm 0.58$ & - & $0.70 \pm 0.76$ & - \\
\hline $32-14$ & $3.20 \pm 0.29$ & - & $0.70 \pm 1.15$ & - \\
\hline G-56 & $2.20 \pm 0.58$ & - & $0.80 \pm 0.58$ & + \\
\hline G-59 & $3.50 \pm 0.00$ & - & $0.80 \pm 0.58$ & + \\
\hline F-54 & $3.80 \pm 0.29$ & - & $0.80 \pm 0.58$ & + \\
\hline C-13 & $4.20 \pm 0.76$ & - & $0.80 \pm 0.58$ & + \\
\hline B-37 & $2.70 \pm 0.76$ & - & $0.80 \pm 0.76$ & - \\
\hline A-51 & $3.20 \pm 0.29$ & - & $1.00 \pm 0.00$ & - \\
\hline L-28 & $2.70 \pm 0.29$ & - & $1.00 \pm 0.50$ & + \\
\hline $\mathrm{C}-52$ & $3.80 \pm 0.58$ & - & $1.00 \pm 0.50$ & + \\
\hline K-19 & $4.00 \pm 0.87$ & - & $1.00 \pm 0.50$ & - \\
\hline $18-16$ & $4.20 \pm 0.29$ & - & $1.00 \pm 1.73$ & - \\
\hline K-46 & $3.20 \pm 0.29$ & - & $1.20 \pm 0.58$ & - \\
\hline $20-11$ & $3.50 \pm 0.50$ & - & $1.20 \pm 0.58$ & + \\
\hline G-58 & $3.80 \pm 0.76$ & - & $1.20 \pm 0.76$ & + \\
\hline PI428109 & $3.00 \pm 0.00$ & - & $1.30 \pm 0.76$ & + \\
\hline G-52 & $4.70 \pm 0.29$ & - & $1.30 \pm 0.76$ & - \\
\hline $20-42$ & $3.30 \pm 0.76$ & - & $1.30 \pm 1.15$ & + \\
\hline L-61 & $3.20 \pm 0.29$ & - & $1.50 \pm 1.00$ & - \\
\hline G-50 & $4.30 \pm 0.29$ & - & $1.50 \pm 1.50$ & + \\
\hline $32-25$ & $3.80 \pm 0.35$ & - & $1.70 \pm 0.29$ & + \\
\hline
\end{tabular}

resistance to tan spot in $T$. dicoccoides. Faris and Friesen (12) identified race nonspecific resistance coming from chromosomes $1 \mathrm{~B}$ and $3 \mathrm{~B}$ rather than $t s n 1$ in a wheat population segregating for Ptr ToxA sensitivity (Tsn1), indicating that Ptr ToxA was not a detectable factor during tan spot development in their population. Among the $T$. dicoccoides accessions investigated in this research, it is possible that resistance in a few accessions is largely due to the presence of the recessive allele at the Tsnl locus, whereas in most other accessions resistance may be due to genes at other loci. Therefore, genes other than $t s n 1$ could play more important roles in governing tan spot resistance in $T$. dicoccoides.

Toxin insensitivity related to SNB disease resistance has also been identified in hexaploid wheat. Liu et al. $(26,27)$ reported a strong correlation between insensitivity to SnTox1 and resistance to SNB. The Snnl locus, which governs SnTox1 sensitivity, coincided with a major QTL that explained up to $58 \%$ of the phenotypic variation. Friesen et al. (18) reported a strong correlation (34 to $68 \%$ ) between SnToxA insensitivity and SNB resistance. Our research also revealed a significant association between insensitivity to HSTs and SNB resistance in $T$. dicoccoides with $40 \%$ of the SNB resistance being associated with SnToxA insensitivity and $7 \%$ of the SNB resistance being associated with culture filtrate insensitivity. Our culture filtrate was derived from Sn2000KO6-1, which has a disrupted form of the ToxA gene (18). Other than SnTox1, Sn2000KO6-1 likely produces additional toxins (T. L. Friesen, unpublished data), and the association between SNB resistance and culture filtrate insensitivity could be due to SnToxl or other unidentified toxins also produced by Sn2000KO6-1.

SNB resistance in $T$. dicoccoides was primarily governed by the $t s n 1$ locus, but other loci governing insensitivity to toxins in the culture filtrate were involved as well. A stronger association between SNB resistance and SnToxA insensitivity indicates that tsnl had greater impact than other loci governing insensitivity to toxins produced in Sn2000KO6-1 culture filtrates. Multiple regression analysis and comparisons of average SNB reactions among toxin-sensitive and insensitive classes indicated that resistance conferred by the $t s n 1$ locus and other toxin insensitivity loci are additive.

Genomic regions related to disease resistance but not associated with known toxin insensitivity loci have been reported As previously mentioned, Faris and Friesen (12) identified tan spot race nonspecific resistance QTL on chromosomes $1 \mathrm{~B}$ and $3 \mathrm{~B}$, but the tsn1 locus on $5 \mathrm{~B}$ was not associated with disease. In addition to $T s c 2$ on $2 \mathrm{BS}$, which governs sensitivity to Ptr ToxB, Friesen and Faris (15) found QTL on chromosomes $2 \mathrm{~A}$ and $4 \mathrm{~A}$ associ- 
Table 2. (continued from previous page)

\begin{tabular}{|c|c|c|c|c|}
\hline Accession $^{a}$ & Tan spot mean & Ptr/Sn ToxA ${ }^{b}$ & $\mathrm{SNB}^{\mathrm{c}}$ mean & Culture filtrate ${ }^{b, d}$ \\
\hline $20-37$ & $3.70 \pm 0.29$ & - & $1.70 \pm 0.76$ & + \\
\hline $20-8$ & $3.50 \pm 0.50$ & - & $1.70 \pm 1.04$ & + \\
\hline $\mathrm{I}-40$ & $2.70 \pm 0.29$ & - & $2.00 \pm 0.00$ & + \\
\hline L-56 & $2.70 \pm 0.29$ & - & $2.00 \pm 0.00$ & + \\
\hline $20-38$ & $3.80 \pm 0.58$ & - & $2.00 \pm 0.00$ & + \\
\hline $\mathrm{I}-44$ & $3.80 \pm 1.04$ & - & $2.00 \pm 0.00$ & + \\
\hline $20-20$ & $4.20 \pm 0.76$ & - & $2.00 \pm 0.50$ & + \\
\hline \multicolumn{5}{|c|}{ Susceptible to both tan spot and SNB } \\
\hline G-11 & $3.30 \pm 0.29$ & + & $2.00 \pm 1.32$ & - \\
\hline $\mathrm{T}-7-18$ & $3.30 \pm 0.29$ & - & $2.20 \pm 0.29$ & + \\
\hline $20-22$ & $3.00 \pm 0.50$ & - & $2.20 \pm 0.58$ & + \\
\hline $20-9$ & $3.20 \pm 0.29$ & - & $2.20 \pm 1.04$ & + \\
\hline G-15 & $3.30 \pm 0.29$ & + & $2.30 \pm 0.29$ & - \\
\hline $20-34$ & $3.70 \pm 0.76$ & + & $2.30 \pm 0.29$ & + \\
\hline G-42 & $4.20 \pm 0.29$ & + & $2.30 \pm 0.29$ & - \\
\hline $20-31$ & $3.50 \pm 0.50$ & - & $2.30 \pm 0.76$ & + \\
\hline G-61 & $3.80 \pm 1.04$ & - & $2.30 \pm 1.61$ & + \\
\hline $32-30$ & $3.30 \pm 0.35$ & - & $2.50 \pm 0.00$ & + \\
\hline $36-25$ & $2.70 \pm 0.76$ & + & $2.70 \pm 0.58$ & + \\
\hline G-22 & $3.50 \pm 0.50$ & + & $2.80 \pm 0.29$ & + \\
\hline $18-56$ & $3.80 \pm 0.29$ & + & $2.80 \pm 0.29$ & + \\
\hline $36-26$ & $3.20 \pm 0.58$ & + & $3.00 \pm 0.00$ & + \\
\hline $36-40$ & $3.20 \pm 0.29$ & + & $3.00 \pm 0.87$ & + \\
\hline T-7-21 & $3.00 \pm 0.00$ & - & $3.00 \pm 1.32$ & + \\
\hline $36-38$ & $3.20 \pm 0.58$ & + & $3.20 \pm 0.29$ & + \\
\hline $36-22$ & $3.30 \pm 0.29$ & + & $3.20 \pm 0.58$ & + \\
\hline $36-39$ & $3.50 \pm 0.50$ & + & $3.20 \pm 1.04$ & + \\
\hline $36-12$ & $3.20 \pm 0.29$ & + & $3.30 \pm 0.29$ & + \\
\hline $36-17$ & $3.20 \pm 0.76$ & + & $3.30 \pm 0.58$ & + \\
\hline $\mathrm{T}-7-5$ & $3.20 \pm 0.29$ & - & $3.30 \pm 1.04$ & + \\
\hline $\mathrm{T}-7-1$ & $3.80 \pm 0.29$ & + & $3.30 \pm 1.61$ & + \\
\hline $36-37$ & $3.20 \pm 0.29$ & + & $3.50 \pm 0.00$ & + \\
\hline $\mathrm{T}-7-8$ & $3.00 \pm 0.00$ & - & $3.70 \pm 0.76$ & + \\
\hline $\mathrm{T}-7-7$ & $3.70 \pm 0.29$ & - & $3.70 \pm 0.76$ & + \\
\hline T-7-45 & $3.30 \pm 0.29$ & + & $3.80 \pm 0.58$ & + \\
\hline $\mathrm{T}-7-15$ & $3.20 \pm 0.29$ & - & $3.80 \pm 1.15$ & + \\
\hline T-7-35 & $3.30 \pm 0.29$ & - & $4.00 \pm 0.50$ & + \\
\hline $36-21$ & $3.20 \pm 0.29$ & + & $4.20 \pm 0.29$ & + \\
\hline $18-10$ & $3.20 \pm 0.58$ & + & $4.20 \pm 0.29$ & + \\
\hline $18-1$ & $3.80 \pm 0.58$ & + & $4.20 \pm 0.29$ & + \\
\hline $\mathrm{T}-7-26$ & $3.50 \pm 0.00$ & + & $5.00 \pm 0.00$ & + \\
\hline $\mathrm{T}-7-30$ & $3.70 \pm 0.29$ & + & $5.00 \pm 0.00$ & + \\
\hline $\mathrm{LSD}_{0.05}$ & 0.71 & & 0.87 & \\
\hline
\end{tabular}

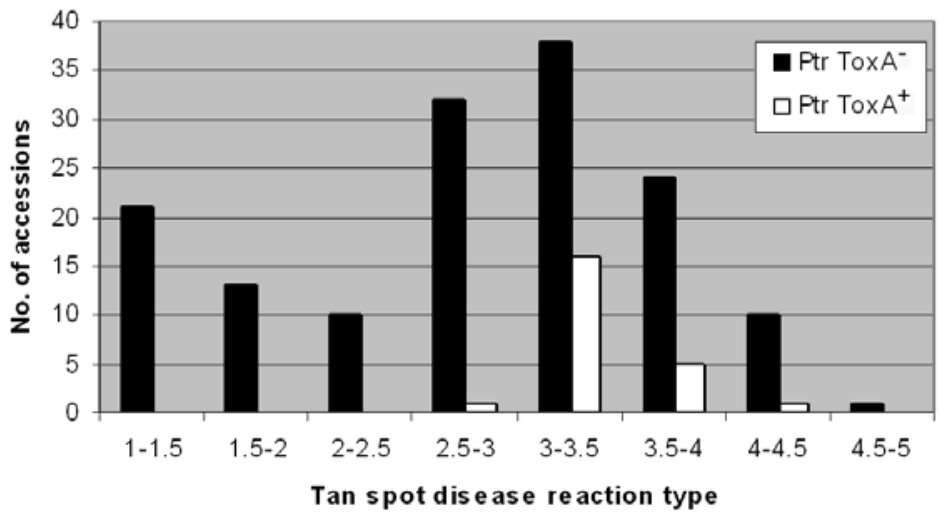

Fig. 2. Histogram of average tan spot disease reaction type frequency comparison of Ptr ToxA sensitive (+) and insensitive (-) accessions in Triticum dicoccoides at the seedling stage.

ated with resistance to tan spot in the ITMI population when inoculating with $\mathrm{Ptr}$ race 5. Liu et al. (27) found several genomic regions other than the snnl locus that were associated with SNB resistance. Friesen et al. (16) also identified SNB resistance from chromosome $5 \mathrm{~A}$ in addition to toxin insensitivity loci. Our results also showed that the resistance/susceptibility to tan spot or SNB in T. dicoccoides was not limited to toxin insensitivity/sensitivity loci. Of the 16 accessions with tan spot reaction types greater than 4.0, only two accessions were sensitive to Ptr ToxA (Table 2). For SNB, some accessions with average disease reaction types around 2.5 (e.g., 18-56
[2.8], 20-34 [2.3], 36-25 [2.7], and G-22 [2.8]) were sensitive to both SnToxA and the Sn2000KO6-1 culture filtrate (Table 2). Therefore, the resistance to $\tan$ spot or SNB in some $T$. dicoccoides accessions could be governed by genes other than the known toxin insensitivity genes. It is possible that the additional resistance loci are actually those conferring insensitivity to undetectable toxins; however, it is just as likely that there are resistance QTL conferring moderate levels of resistance that have no association with toxin insensitivity. Therefore, the $T$. dicoccoides accessions that have resistance/susceptibility unrelated to known toxin insensitivities/ sensitivities would be especially useful for either identifying new toxins or characterizing different types of resistance in this host-pathogen system.

T. dicoccoides has been shown to be a good genetic source for resistance to powdery mildew, leaf rust, stem rust, and Fusarium head blight, as well as increased seed storage protein content $(4,20,36,44)$. However, T. dicoccoides does have some drawbacks due to its exotic nature including shattering, later-maturing, and nonfree threshing traits (6). According to the results presented here, elimination of toxin sensitivities will increase the level of both SNB and tan spot resistance but may have a greater effect on resistance to SNB because it is more strongly associated with insensitivity to HSTs produced by its corresponding fungus than is tan spot. Furthermore, elimination of ToxA sensitivity (Tsn1) could increase resistance to both diseases. Other than insensitivity to toxins, T. dicoccoides likely harbors resistance to both SNB and tan spot that will increase the base of resistance in tetraploid wheat. Evidence of this is found in lines that are toxin sensitive but still maintain a high or moderate level of resistance. These include Ptr ToxA-sensitive accession 36-25 having an average tan spot reaction type of 2.7, SnToxA-sensitive accessions 18-20 and G11 having average SNB reaction types of 0.2 and 2.0, respectively, and several accessions with SNB reaction types of around 2.5 (18-56, 20-34, 36-25, and G22) being sensitive to both SnToxA and $S$. nodorum culture filtrate.

In summary, from $172 T$. dicoccoides accessions, we identified a number of accessions with good resistance to tan spot and SNB, and 31 accessions showed good resistance to both diseases. Based on the association analysis between HST insensitivity and resistance to the pathogen, the resistance in $T$. dicoccoides involves toxin insensitivity loci as well as other uncharacterized genes, and it is therefore a potentially new source of resistance for cultivated wheat. Data in this article present useful information for the selection of parental lines for either producing resistant germplasm or for developing mapping populations for the characterization of 
Table 3. Two sample $t$ test to compare the difference of average reactions to Pyrenophora tritici-repentis (Ptr) and Stagonospora nodorum (Sn) according to the reactions to host selective toxins (HSTs) in 172 Triticum dicoccoides accessions

\begin{tabular}{|c|c|c|c|c|c|}
\hline Comparison $^{a}$ & Mean1 $^{b}$ & Mean2 $^{\text {b }}$ & Difference $^{c}$ & $t$ value & $P^{d}$ \\
\hline \multicolumn{6}{|l|}{ Reaction to $P$. tritici-repentis } \\
\hline Ptr ToxA- vs. Ptr ToxA ${ }^{+}$ & $2.89(149)$ & $3.41(23)$ & 0.52 & 6.87 & $<0.0001$ \\
\hline \multicolumn{6}{|l|}{ Reaction to $S$. nodorum } \\
\hline SnToxA $^{-}$vs. SnToxA ${ }^{+}$ & 0.84 (149) & $3.17(23)$ & 2.33 & 18.28 & $<0.0001$ \\
\hline $\mathrm{CF}^{-}$vs. $\mathrm{CF}^{+}$ & $0.70(64)$ & $1.41(108)$ & 0.71 & 7.37 & $<0.0001$ \\
\hline SnToxA $^{-} \mathrm{CF}^{-}$vs. SnToxA ${ }^{-} \mathrm{CF}^{+}$ & $0.63(60)$ & $0.98(89)$ & 0.35 & 4.16 & $<0.0001$ \\
\hline SnToxA $^{+} \mathrm{CF}^{-}$vs. SnToxA $\mathrm{A}^{+} \mathrm{CF}^{+}$ & $1.71(4)$ & $3.54(18)$ & 1.83 & 6.38 & $<0.0001$ \\
\hline SnToxA $^{-} \mathrm{CF}^{-}$vs. SnToxA ${ }^{+} \mathrm{CF}^{-}$ & $0.63(60)$ & $1.71(4)$ & 1.08 & 5.00 & $<0.0001$ \\
\hline SnToxA $^{-} \mathrm{CF}^{+}$vs. SnToxA $\mathrm{A}^{+} \mathrm{CF}^{+}$ & $0.98(89)$ & $3.54(18)$ & 2.56 & 16.35 & $<0.0001$ \\
\hline
\end{tabular}

a Insensitivity and sensitivity to host selective toxins are indicated by - and +, respectively; CF = culture filtrate from Sn2000KO6-1.

b Mean 1 and Mean2 are the average disease reaction types of the first and second components in the comparison, respectively. Numbers of accessions used for each mean are indicated in parentheses.

c Difference is calculated by Mean2 minus Mean1.

d Probability associated with the $t$ value from two-sample $t$ test.
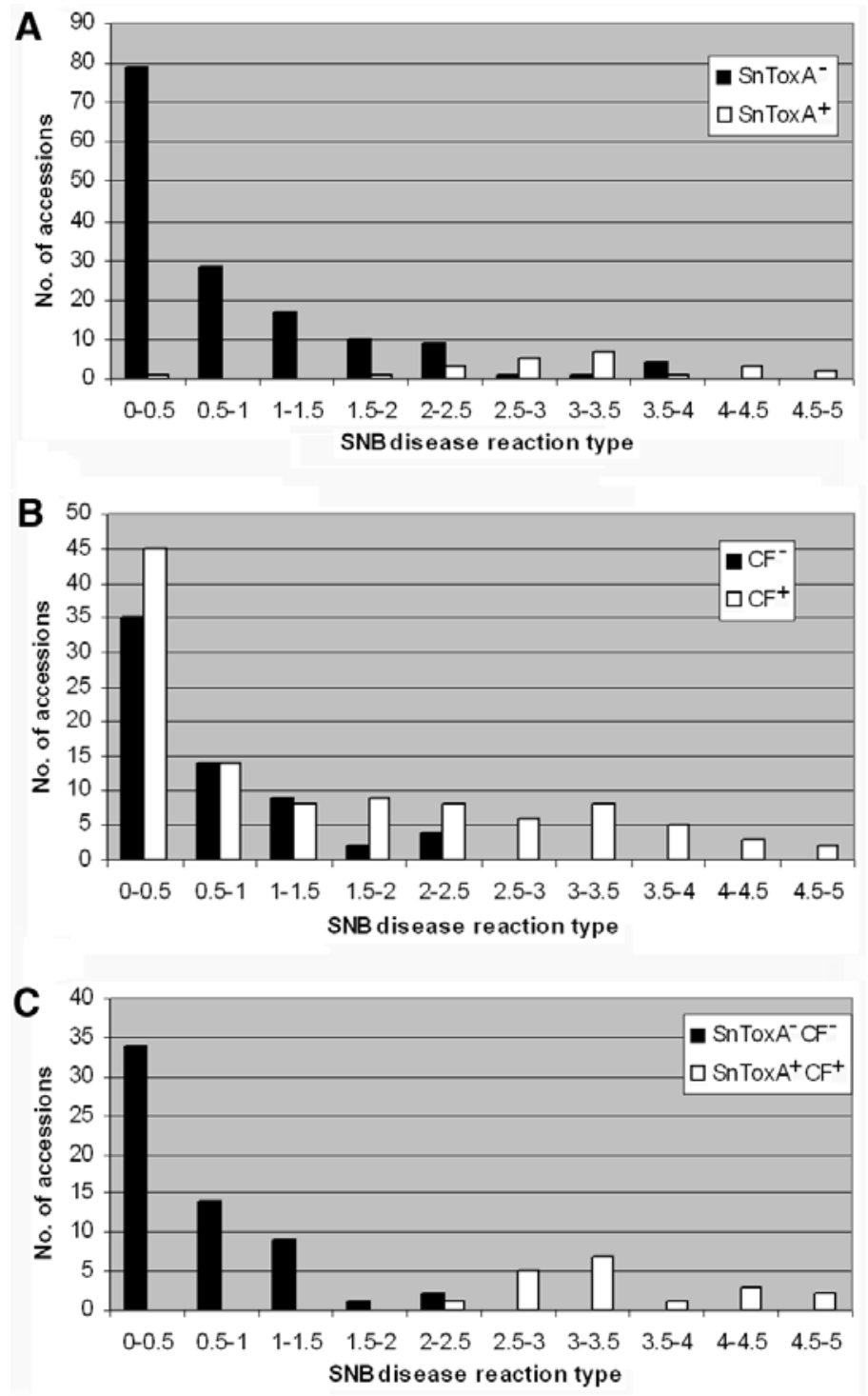

Fig. 3. Histogram of average Stagonospora nodorum blotch (SNB) disease reaction type frequency comparison of Ptr ToxA and/or Sn2000KO6-1 culture filtrate (CF) sensitive (+) and insensitive ( - ) accessions in Triticum dicoccoides at the seedling stage. A, Ptr ToxA sensitive and insensitive; $\mathbf{B}$, culture filtrate sensitive and insensitive; and $\mathbf{C}$, both Ptr ToxA and culture filtrate sensitive and insensitive.

resistance found in these accessions. Data presented here also provide evidence for the usefulness of screening early germplasm with both purified toxins and crude culture filtrates as a preliminary screen for disease resistance. The $T$. dicoccoides accessions are currently maintained and can be obtained by contacting Steven Xu at the USDA-ARS, Northern Crop Science Laboratory, Fargo, ND.

\section{ACKNOWLEDGMENTS}

The authors thank Xiwen Cai and Shaukat Ali for critical review and S. W. Meinhardt for providing purified Ptr ToxA. This research was supported by USDA-ARS CRIS 5442-22000-043-00D and 5442-22000-030-00D

\section{LITERATURE CITED}

1. Alam, K. B., and Gustafson, J. P. 1988. Tanspot resistance screening of Aegilops species. Plant Breed. 100:112-118.

2. Ali, S., and Francl, L. J. 2003. Population race structure of Pyrenophora tritici-repentis prevalent on wheat and noncereal grasses in the Great Plains. Plant Dis. 87:418-422.

3. Anderson, J. A., Effertz, R. J., Faris, J. D., Francl, L. J., Meinhardt, S. W., and Gill, B. S 1999. Genetic analysis of sensitivity to a Pyrenophora tritici-repentis necrosis-inducing toxin in durum and common wheat. Phytopathology 89:293-297.

4. Anikster, Y., Manisterski, J., Long, D. L., and Leonard, K. J. 2005. Leaf rust and stem rust resistance in Triticum dicoccoides populations in Israel. Plant Dis. 89:55-62.

5. Balance, G. M., Lamari, L., and Bernier, C. C. 1989. Purification and characterization of a host selective toxin from Pyrenophora triticirepentis. Physiol. Mol. Plant Pathol. 35:203213.

6. Cantrell, R. G., and Joppa, L. R. 1991. Genetic analysis of quantitative traits in wild emmer (Triticum turgidum L. var. dicoccoides). Crop Sci. 31:645-649.

7. Dyck, P. L. 1994. The transfer of leaf rust resistance from Triticum turgidum ssp. dicoccoides to hexaploid wheat. Can. J. Plant Sci. 74:671-673.

8. Ecker, R., Cahaner, A., and Dinoor, A. 1990 The inheritance of resistance to Septoria nodorum blotch. II. The wild wheat species Aegilops speltoides. Plant Breed. 104:218-223.

9. Ecker, R., Cahaner, A., and Dinoor, A. 1990. The inheritance of resistance to Septoria nodorum blotch. III. The wild wheat species Aegilops longissima. Plant Breed. 104:224230.

10. Effertz, R. J., Meinhardt, S. W., Anderson, J. A., Jordahl, J. G., and Francl, L. J. 2002. Identification of a chlorosis-inducing toxin from Pyrenophora tritici-repentis and the chromosomal location of an insensitivity locus in wheat. Phytopathology 92:527-533.

11. Faris, J. D., Anderson, J. A., Francl, L. J., and Jordahl, J. G. 1996. Chromosomal location of a gene conditioning insensitivity in wheat to a necrosis-inducing culture filtrate from Pyrenophora tritici-repentis. Phytopathology 86:459463.

12. Faris, J. D., and Friesen, T. L. 2005. Identification of quantitative trait loci for racenonspecific resistance to $\tan$ spot in wheat 
Theor. Appl. Genet. 111:386-392.

13. Fried, P. M., and Meister, E. 1987. Inheritance of leaf and head resistance of winter wheat to Septoria nodorum in a diallel cross. Phytopathology 77:1371-1375.

14. Friesen, T. L., Ali, S., Kianian, S., Francl, L. J., and Rasmussen, J. B. 2003. Role of host sensitivity to Ptr ToxA in development of tan spot of wheat. Phytopathology 93:397-401.

15. Friesen, T. L., and Faris, J. D. 2004. Molecular mapping of resistance to Pyrenophora triticirepentis race 5 and sensitivity to Ptr ToxB in wheat. Theor. Appl. Genet. 109:464-471.

16. Friesen, T. L., Meinhardt, S. W., and Faris, J. D. 2007. The Stagonospora nodorum-wheat pathosystem involves multiple proteinaceous host-selective toxins and corresponding host sensitivity genes that interact in an inverse gene-for-gene manner. Plant J. 51:681-692.

17. Friesen, T. L., Rasmussen, J. B., Kwon, C. Y., Ali, S., Francl, L. J., and Meinhardt, S. W. 2002. Reaction of Ptr ToxA-insensitive wheat mutants to Pyrenophora tritici-repentis race 1. Phytopathology 92:38-42.

18. Friesen, T. L., Stukenbrock, E. H., Liu, Z., Meinhardt, S., Ling, H., Faris, J. D., Rasmussen, J. B., Solomon, P. S., McDonald, B. A., and Oliver, R. P. 2006. Emergence of a new disease as a result of virulence gene transfer. Nat. Genet. 38:953-956.

19. Friesen, T. L., Zhang, Z. C., Solomon, P. S., Oliver, R. P., and Faris, J. D. 2008. Characterization of the interaction of a novel Stagonospora nodorum host-selective toxin with a wheat susceptibility gene. Plant Physiol. 146:682-693.

20. Joppa, L. R., Du, C., Hart, G. E., and Hareland, G. A. 1997. Mapping gene(s) for grain protein in tetraploid wheat (Triticum turgidum L.) using a population of recombinant inbred chromosome lines. Crop Sci. 37:1586-1589.

21. Joppa, L. R., Nevo, E., and Beiles, A. 1995. Chromosome translocations in wild populations of tetraploid emmer wheat in Israel and Turkey. Theor. Appl. Genet. 91:713-719.

22. Lamari, L., and Bernier, C. C. 1989. Evaluation of wheat lines and cultivars to tan spot [Pyrenophora tritici-repentis] based on lesion type. Can. J. Plant Pathol. 11:49-56.

23. Lamari, L., and Bernier, C. C. 1991. Genetics of tan necrosis and extensive chlorosis in tan spot of wheat caused by Pyrenophora triticirepentis. Phytopathology 81:1092-1095.

24. Lamari, L., McCallum, B. D., and DePauw, R. M. 2005. Forensic pathology of Canadian bread wheat: The case of tan spot. Phytopathology 95:144-152.

25. Lamari, L., Strelkov, S. E., Yahyaoui, A., Orabi, J., and Smith, R. B. 2003. The identification of two new races of Pyrenophora triticirepentis from the host center of diversity confirms a one-to-one relationship in tan spot of wheat. Phytopathology 93:391-396.

26. Liu, Z. H., Faris, J. D., Meinhardt, S. W., Ali, S., Rasmussen, J. B., and Friesen, T. L. 2004.
Genetic and physical mapping of a gene conditioning sensitivity in wheat to a partially purified host-selective toxin produced by Stagonospora nodorum. Phytopathology 94:10561060.

27. Liu, Z. H., Friesen, T. L., Rasmussen, J. B., Ali, S., Meinhardt, S. W., and Faris, J. D. 2004. Quantitative trait loci analysis and mapping of seedling resistance to Stagonospora nodorum leaf blotch in wheat. Phytopathology 94:10611067.

28. Ma, H., and Hughes, G. R. 1993. Resistance to Septoria nodorum blotch in several Triticum species. Euphytica 70:151-157.

29. Ma, H., and Hughes, G. R. 1995. Genetic control and chromosomal location of Triticum timopheevii-derived resistance to Septoria nodorum blotch in durum wheat. Genome 38:332-338.

30. Manning, V. A., Pandelova, I., and Ciuffetti, L. M. 2002. A race for a novel host selective toxin. (Abstr.) Phytopathology 92:S51.

31. Martinez, J. P., Ottum, S. A., Ali, S., Francl, L. J., and Ciuffetti, L. M. 2001. Characterization of ToxB gene from Pyrenophora triticirepentis. Mol. Plant-Microbe. Interact. 14:675677.

32. Meinhardt, S., Ali, S., Ling, H., and Francl, L. 2003. A new race of Pyrenophora triticirepentis that produces a putative hostselective toxin. Pages 117-121 in: Proc. Int. Wheat Tan Spot Spot Blotch Workshop, 4th. J. B. Rasmussen, T. L. Friesen, and S. Ali, eds. North Dakota Agric. Exp. Stn., Fargo, ND, USA

33. Mergoum, M., Singh, P. K., Ali, S., Elias, E. M., Anderson, J. A., Glover, K. D., and Adhikari, T. B. 2007. Reaction of elite wheat genotypes from the northern Great Plains of North America to Septoria diseases. Plant Dis. 91:1310-1315.

34. Nevo, E., and Beiles A. 1989. Genetic diversity of wild emmer wheat in Israel and Turkey. Theor. Appl. Genet. 77:421-455.

35. Nevo, E., Golenberg, E. M., Beiles, A., Brown, A. H. D., and Zohary, D. 1982. Genetic diversity and environmental associations of wild wheat, Triticum dicoccoides in Israel. Theor. Appl. Genet. 62:241-254.

36. Nevo, E., Moseman, J. G., Beiles, A., and Zohary, D. 1985. Patterns of resistance of Israeli wild emmer wheat to pathogens: I. Predictive method by ecology and allozyme genotypes for powdery mildew and leaf rust. Genetica 67:209-222.

37. Orolaza, N. P., Lamari, L., and Balance, G. M. 1995. Evidence of a host specific chlorosis toxin from Pyrenophora tritici-repentis, the causal agent of tan spot of wheat. Phytopathology 85:1282-1287.

38. Perello, A., Moreno, V., Simon, M. R., and Sisterna, M. 2003. Tan spot of wheat infection at different stages of crop development and inoculum type. Crop Prot. 22:157-169.

39. Rees, R. G., and Platz, G. J. 1990. Sources of resistance to Pyrenophora tritici-repentis in bread wheats. Euphytica 45:59-69.

40. Riede, C. R., Francl, L. J., Anderson, J. A., Jordahl, J. G., and Meinhardt, S. W. 1996. Ad ditional source of resistance to tan spot of wheat. Crop Sci. 36:771-777.

41. SAS Institute. 1999. SAS/STAT User's Guide, Releases: 8.2, 8.1, 8.0. SAS Institute, Inc., Cary, NC.

42. Singh, P. K., Mergoum, M., Ali, S., Adhikari, T. B., Elias, E. M., Anderson, J. A., Glover, K D., and Berzonsky, W. A. 2006. Evaluation of elite wheat germ plasm for resistance to tan spot. Plant Dis. 90:1320-1325.

43. Singh, P. K., Mergoum, M., Ali, S., Adhikari, T. B., Elias, E. M., and Hughes, G. R. 2006. Identification of new sources of resistance to tan spot, stagonospora nodorum blotch, and septoria tritici blotch of wheat. Crop Sci. 46:2047-2053.

44. Stack, R. W., Elias, E. M., and Joppa, L. R. 1999. Fusarium head blight reaction of durum wheat lines conditioned by Triticum di coccoides chromosome substitutions. (Abstr.) Phytopathology 89:S74.

45. Tadesse, W., Hsam, S. L. K., and Zeller, F. J. 2006. Evaluation of common wheat cultivars for tan spot resistance and chromosomal location of a resistance gene in the cultivar 'Salamouni'. Plant Breed. 125:318-322.

46. Tekauz, A., Mueller, E., Stulzer, M., and Schultz, D. 2004. Leaf spot diseases of winter wheat in Manitoba in 2003. Can. Plant Dis. Surv. 83:73-74

47. Tomás, A., and Bockus, W. W. 1987. Cultivar specific toxicity of culture filtrate of Pyrenophora tritici-repentis. Phytopathology 77:13371366

48. Tomás, A., Feng, G. H., Reeck, G. R., Bockus, W. W., and Leach, J. E. 1990. Purification of a cultivar-specific toxin from Pyrenophora tritici-repentis, causal agent of tan spot of wheat. Mol. Plant-Microbe. Interact. 3:221 224.

49. Tuori, R. P., Wolpert, T. J., and Ciuffetti, L. M. 1995. Purification and immunological characterization of toxic components from cultures of Pyrenophora tritici-repentis. Mol. PlantMicrobe. Interact. 8:41-48.

50. Valkoun, J. J. 2001. Wheat pre-breeding using wild progenitors. Euphytica 119:17-23.

51. Xu, S. S., Friesen, T. L., and Mujeeb-Kazi, A. 2004. Seedling resistance to tan spot and Stagonospora nodorum blotch in synthetic hexaploid wheats. Crop Sci. 44:2238-2245.

52. Zhang, H. F., Francl, L. J., Jodahl, J. G., and Meinhardt, S. W. 1997. Structural and physical properties of a necrosis-inducing toxin from Pyrenophora tritici-repentis. Phytopathology 87:541-560.

53. Zohary, D. 1970. Centers of diversity and centers of origin. Pages 33-44 in: Genetic Resources in Plants - Their Exploration and Conservation. O. H. Frankel and E. Bennet, eds. Blackwell Publishing, Oxford 